\title{
A survey of the management of 16-18-year-olds presenting with diabetic ketoacidosis in the UK: a need for standardisation
}

\author{
KETAN DHATARIYA, ${ }^{1,2}$ PETER WINOCOUR, ${ }^{3}$ ANDREW RAFFLES ${ }^{4}$
}

\begin{abstract}
Background: The standard of care of 16-18-year-olds presenting with diabetic ketoacidosis (DKA) is uncertain. It is unknown who looks after them or what guidelines are used to manage their DKA.

Methods: We carried out a survey using a standardised questionnaire sent to diabetes and emergency care teams across the UK using mailing lists from the Association of British Clinical Diabetologists, The Diabetes Specialist Nurse Group (UK) and the British Society of Paediatric Endocrinology and Diabetes.
\end{abstract}

Results: There was a relatively poor response rate; only 32 completed questionnaires were received between May and November 2018. The data suggest that the care was highly variable across the UK. There were no consistencies on how '16-18 years old' was defined; who looked after them either during the acute phase once they had been triaged through the emergency department or during the later stages of their admission; or what guideline was used to treat their DKA. Several other aspects of care were also varied.

Conclusions: The care of 16-18-year-olds presenting with DKA needs to be standardised across the UK. Furthermore, because a large number are looked after by adult nonspecialist general medical teams, there is a clear need to ensure a consistent straightforward joint guideline that

Elsie Bertram Diabetes Centre, Norfolk and Norwich University Hospitals NHS Foundation Trust, Norwich, Norfolk, UK

Norwich Medical School, University of East Anglia, Norwich, Norfolk, UK Department of Diabetes and Endocrinology, East and North Hertfordshire NHS Trust, Lister Hospital, Stevenage, Hertfordshire, UK

${ }^{4}$ Department of Children's Services, East and North Hertfordshire NHS

Trust, Lister Hospital, Stevenage, Hertfordshire, UK

Address for correspondence: Professor Ketan Dhatariya

Consultant in Diabetes and Endocrinology, Elsie Bertram Diabetes

Centre, Norfolk and Norwich University Hospitals NHS Foundation Trust,

Colney Lane, Norwich, Norfolk NR4 7UY, UK

Tel: $+44(0) 1603288170$

Fax: $+44(0) 1603287320$

E-mail: ketan.dhatariya@nnuh.nhs.uk

https://doi.org/10.15277/bjd.2019.204 can be readily applied in all acute clinical settings regardless of whether care takes place in a paediatric or an adult clinical setting.

Br J Diabetes 2019;19:29-33

Key words: diabetic ketoacidosis; management; standardisation; adolescent

\section{Introduction}

The prevalence of diabetic ketoacidosis (DKA) among children and adolescents remains high and is stated as being between $1 \%$ and $10 \%$ per patient per year in those with established type 1 diabetes. ${ }^{1-7}$ In the UK, the standard of care for people under the age of 18 years presenting with DKA should be the 2015 guidelines from the British Society of Paediatric Endocrinology and Diabetes (BSPED)/Association of Children's Diabetes Clinicians (ACDC) or the International Society of Pediatric and Adolescent Diabetes (ISPAD). 8,9 This is in contrast to those aged over 18 years, who should be treated by the guidelines produced by the Joint British Diabetes Societies (JBDS). ${ }^{10}$

However, in the UK, the care of those aged between 16 and 18 years is felt not to be consistent. Anecdotally, many would be treated as an outpatient by the paediatric or transitional diabetes team, yet when they present to hospital with DKA, they may be admitted under the adult teams. Adult teams would be more familiar with the JBDS guideline and would not be as comfortable using the BSPED or ISPAD guidelines that have been developed for this age group.

To determine current practice across the UK, a survey was sent out using social media to diabetes and emergency teams to gauge the care for 16-18-year-olds.

\section{Methods}

In May 2018 a questionnaire was sent out to all diabetes and emergency care teams across the UK using mailing lists from the Association of British Clinical Diabetologists, The Diabetes Specialist Nurse Group (UK) and BSPED. In the previous audits on the management of DKA, 220 adult teams and 185 paediatric teams were contacted. ${ }^{11,12}$ The aim was to get diabetes teams and individuals working in emergency departments (adult and paediatric) to return completed questionnaires. Input was specif- 
ically sought from those working 'at the front door' who first looked after these admissions. This was to prevent any misconceptions arising from the most senior staff who may be more remote from the initial admission and only see people once they had been treated for a few hours. A questionnaire was developed by the authors after discussion and is shown in Appendix 1 (available online www.bjd-abcd.com). Reminders were sent out twice during the data collection period. The results and individual comments were collated.

\section{Results}

Disappointingly, only 32 completed questionnaires were returned during the 6 months of follow-up. However, they were from all parts of the UK, from all sizes of hospital and were from a variety of teams - adult and paediatric diabetes teams and from the emergency department.

\section{Who filled out the form?}

Twenty-one of the forms were completed by consultants and nine were completed by specialist trainees. The others were completed by Trust grade doctors, adult or paediatric diabetes specialist nurses.

\section{How is '16-18 years old' defined in your institution?}

Seventeen teams felt that ' $16-18$ years old' meant from the day they turned 16 to the day they turned 18 years. Nine teams, however, felt it was from the day an individual turned 16 to the day before they turned 19 years. Three respondents did not know how it was defined in their institution; the rest all replied that 'it varies'.

If a 16-18-year-old is admitted to your hospital with suspected or biochemically confirmed diabetic ketoacidosis, which team are they most likely to be handed over to by the emergency department?

Six teams handed 16-18-year-old patients presenting with DKA to the adult diabetes team for further management, four teams handed them to the paediatric diabetes team, and two and five departments, respectively, handed them to the general adult or paediatric medical team on call. Fifteen teams, however, had no consistent policy and used a combination of teams to refer to after admission from the emergency department. One reply suggested that the individual would be triaged to the paediatric team if they were already known to them, otherwise they would be admitted under the adult team.

Once they are stabilised and ready to go to a general ward, which team would they be admitted under?

The answers to this question were varied, and the team who took them after initial triage was not always the same as the team who looked after them for the duration of their inpatient stay. In six institutions, 16-18-year-olds were looked after by the adult diabetes team; in two of these hospitals the respondents had suggested that the initial team under which these individuals would have been admitted was variable. In a further six it was the paediatric diabetes team who would be the team under whom they were admitted - in one of these cases, handed over by the general paediatric team who they were triaged to during the acute phase of the admission after the emergency department had triaged them. In four institutions the general adult medical team would continue to look after them and in six it would be the general paediatric team. In four of these 10 institutions it was reported that they would have been looked after by a 'combination' of admitting teams after initial triage from the emergency department. For the remainder, where there has been a combination of answers about who the emergency department handed them over to, they remained under a 'combination'.

\section{If a 16-18-year-old is admitted to your hospital with} suspected or biochemically confirmed DKA, what guideline do you use to manage it?

Nineteen teams said they would use the BSPED/ACDC guidelines. Five respondents said they would use the JBDS guideline, even though that explicitly says it is only for use in those over 18 years old. The remainder used a combination of either Trustspecific $(n=5)$ or regional guidelines $(n=2)$.

Do the adult teams treating 16-18-year-olds know about the BSPEDIACDCIISPAD guidelines?

Thirteen respondents said 'yes', the adult teams did use the paediatric guidelines, one respondent said 'no', but the majority $(n=15)$ did not know the answer to this question.

If the adult teams looking after 16-18-year-olds with DKA know about the BSPEDIACDC/ISPAD guidelines, why are they not used?

For the teams for whom this answer was relevant, four respondents felt that the paediatric guidelines were too complicated $(n=2)$ or that the JBDS guidelines were easier to use $(n=2)$. Five teams said that they were not used frequently enough. Some other replies suggested that the use of the appropriate guideline depended on who was on call (ie, user-dependent).

Do the paediatric teams ever use the adult (JBDS) guideline for 16-18-year-olds?

Only one team said 'yes', the majority $(n=19)$ said ' $n o$ ', whilst the remainder who replied $(n=12)$ answered 'do not know'.

\section{Why do paediatric teams use the adult (JBDS) guideline for} 16-18-year-olds?

Here the answers varied. The majority of respondents $(n=19)$ felt this was not applicable or was unanswered $(n=6)$. However, for those who did reply, one responded that the paediatric team were unaware of the BSPED/ACDC/ISPAD guidelines and two teams felt that 16 -year-olds were treated as adults.

Do you think that a joint guideline for managing DKA in children and adults would be useful?

Eleven respondents said 'yes - definitely', a further nine said 'yes 
- maybe', three were not sure, six said 'no - probably not' and two said 'no - definitely'. Two respondents left this unanswered. Several comments were also received, for example:

- "Paediatricians need to use one guideline that they are familiar with" (no - probably not)

- "The different aspects of care for the children and adults would need to be made explicit" (yes - maybe)

- "Need more evidence-based treatment" (yes - definitely)

- "There have been disagreements when individuals seen in the paediatric outpatients only until that time come in with DKA over 16 years old and the paediatricians refuse to see them, and so do the adult teams because they are not known to them - the medical director has had to be involved" (yes - definitely).

- "Some 16-year-olds have the height and weight of an adult whilst some 18-year-olds have the height and weight of a child" (yes - definitely)

- "It will probably be too lengthy and might get very confusing as well for staff to follow" (no - probably not)

Do you routinely weigh patients admitted with DKA aged $0-15$ years old?

Other than six teams who did not answer, all of the respondents said 'yes'.

Do you routinely weigh patients admitted with DKA aged $16-18$ years old?

Four teams did not answer, five teams said 'no' and the rest said they did weigh 16-18-year-olds.

Do you routinely weigh patients admitted with DKA aged over 18 years?

Seven teams did not answer this question. Of the remainder, nine teams said 'no' and 17 teams said 'yes'.

In your emergency department where 16-18-year-olds are treated for DKA, is $0.9 \%$ sodium chloride solution available? Other than two teams who did not answer, all of the respondents said 'yes'.

In your emergency department where 16-18-year-olds are treated for DKA, is $0.45 \%$ sodium chloride solution available?

Four teams left this unanswered, three teams said 'no, it was unavailable' and the remaining 26 said it was available.

In your emergency department where 16-18-year-olds are treated for DKA, is $2.7 \%$ sodium chloride solution available?

Seven teams left this unanswered, 11 teams said 'no', and the remaining 14 said it was available.

In your emergency department where 16-18-year-olds are treated for DKA, is $3.0 \%$ sodium chloride solution available?
Eight teams left this unanswered, 10 teams said 'no' and the remaining 15 said it was available.

In your emergency department where 16-18-year-olds are treated for DKA, is mannitol available?

Six teams left this unanswered, two teams said 'no' and the remaining 25 said it was available.

Does your institution allow for paediatric and adult joint working - for example, do you have a joint guideline or an inpatient paediatric/adolescent/adult multidisciplinary team that sees these inpatients together?

Five teams said they had joint working between adults and paediatric teams, 21 said they did not and six of the respondents did not know. Comments included that joint working was only in the outpatient clinic, not during acute admissions, or that the adult team only got involved if the individual was not improving.

In your institution are 16-18-year-olds formally reviewed by the diabetes specialist team (adult or adolescent) prior to discharge?

The majority of teams ( $n=25)$ said 'yes' while the remainder said either 'don't know' ( $n=6)$ or 'sometimes' $(n=1)$.

\section{Discussion}

This small survey has shown that the care of 16-18-year-olds presenting with DKA is highly variable across the UK. Despite the availability of national and international guidelines, there remain huge variations in standards of care - starting with how '16-18-year-olds' is defined.

It has been recommended that that the general diabetes care of 16-18-year-olds should be done by specialist multidisciplinary paediatric or transition teams in outpatients. ${ }^{13-16}$ However, when a person in this age group is admitted to hospital as an acute emergency, our data show that the seamless multidisciplinary care that is recommended does not occur uniformly. This could cause problems because, as indicated, these individuals may be admitted under the care of the adult general or diabetes teams. These teams would be more used to looking after those aged over 18 years and thus use the JBDS guideline. Few of the adult teams (in particular the non-specialist teams who may look after the individuals during the acute admission until they could be handed over to the specialist diabetes team) may be familiar with the paediatric guidelines.

The wide variation in 'normal' weight in boys and girls aged 18 means that it is clear that there should not be a 'one size fits all' policy. ${ }^{17}$ Thus there are boys who are over $100 \mathrm{~kg}$, just as there are girls just over $40 \mathrm{~kg}$, who fall between the 0.4 th and 99.6th centile. ${ }^{17}$ Equally, as adults there are wide variations in weight. This is one of the reasons why the adult guideline from the JBDS moved to the weight-based fixed rate intravenous insulin infusion (FRIII) because the question that arose was 'when does a child become an adult'? With these wide weight differences, the weight-based solution seemed appropriate and 


\section{Key messages}

What is already known on this topic

- 16-18-year-olds with diabetes mellitus are commonly looked after by paediatric or transition teams when they are seen as outpatients.

- When admitted into hospital with DKA, there are differences in who looks after them - general or specialist paediatric teams, or general or specialist adult teams

\section{What this study adds}

- That there is little consistency across the UK on where and who should manage this group of individuals

- Adult or paediatric teams - generalists or specialists look after 16-18-year-olds using a variety of guidelines to do so e.g. JBDS or BSPED

- An interim solution is that when a 16-18-year-old is admitted under the adult team then they should be treated using the JBDS guideline, if they are admitted under the paediatric team, they should be treated with the BSPED/ISPAD guideline

currently there seems to be little evidence of harm. ${ }^{11}$

If the weight-based FRIII is similar, this then led to the question about whether a common guideline should be developed. The data suggest some resistance to this idea. However, we did not explore the reasons for this in any depth. It may well be that the resistance stems from the fact that for many years there has been a reluctance to use rapid fluid replacement or high sodium-containing replacement fluid in young people because of the perceived risk of cerebral oedema. ${ }^{18}$ However, recent data have suggested that these risks may be less than previously thought, although often unpredictable. ${ }^{19}$ Thus a common guideline may be possible. As with the adult JBDS guideline that was initially introduced in 2011, there may be a short period of 'getting to know you', but after a while the adult guideline has been adapted or adopted by over $90 \%$ of all UK hospitals and has been rated as 'good' or 'excellent', and as improving patient care. ${ }^{20}$

There are some limitations to our data. The questionnaire that we developed was not validated and was the result of informal discussions between the authors - all of whom are experienced adult (PW and $K D$ ) or paediatric (AR) endocrinologists with an interest in DKA. The sample size was small; despite sending out the questionnaire (including two reminders) to all diabetes teams across the UK in a manner similar to that used for a previous national survey ${ }^{11}$ with the addition of the paediatric diabetes networks, we had a low response rate. We are unsure why this may be and is likely to influence our results. However, despite the low response rate, the huge variation in replies is of concern.
We suggest that any new guidance that is produced explicitly states several issues:

a) What '16-18 years old' means

b) Who should be responsible for the care of this age group when they are admitted to hospital - possibly depending on who has looked after them most recently as an outpatient

c) Whether any guideline that is used should be age-based or weight-based

d) A framework for joint working between the paediatric and adult teams during the inpatient stay and after discharge.

In summary, our data highlight the large variation in the care provided to 16-18-year-olds presenting with DKA across the UK. These data should act as a starting point for those organisations responsible for producing the guidelines on the management of DKA in this age group to be more explicit in several areas. As an interim measure, after a meeting of the DKA specialist interest group at the Royal College of Physicians and Child Health in February 2019, an intermediate solution was agreed, that would be that 16-18-year-olds admitted under adult teams would be treated using the JBDS protocol, and if they were admitted under the paediatric teams, they would be treated using the BSPED/ISPAD protocol. Formal ratification of this is awaited.

\section{Conflict of interest None. \\ Funding None.}

\section{References}

1. Hanas R, Lindgren F, Lindblad B. A 2-yr national population study of pediatric ketoacidosis in Sweden: predisposing conditions and insulin pump use. Pediatr Diabetes 2009;10(1):33-7. https://doi.org/10.1111/j.13995448.2008.00441.x

2. Rosilio M, Cotton JB, Wieliczko MC, et al. Factors associated with glycemic control: a cross-sectional nationwide study in 2,579 French children with type 1 diabetes. The French Pediatric Diabetes Group. Diabetes Care 1998; 21(7):1146-53. https://doi.org/10.2337/diacare.21.7.1146

3. Smith CP, Firth D, Bennett $S$, Howard C, Chisholm P. Ketoacidosis occurring in newly diagnosed and established diabetic children. Acta Paediatr 1998; 87(5):537-41. https://doi.org/10.1111/j.1651-2227.1998.tb01499.x

4. Morris AD, Boyle DI, McMahon AD, Greene SA, MacDonald TM, Newton RW. Adherence to insulin treatment, glycaemic control, and ketoacidosis in insulin-dependent diabetes mellitus. Lancet 1997;350:1505-10. https://doi.org/10.1016/S0140-6736(97)06234-X

5. Duca LM, Reboussin BA, Pihoker C, et al. Diabetic ketoacidosis at diagnosis of type 1 diabetes and glycemic control over time: the SEARCH for Diabetes in Youth study. Pediatr Diabetes 2019;20(2):172-9. https://doi.org/ 10.1111/pedi.12809.

6. Maahs DM, Hermann JM, Holman N, et al. Rates of diabetic ketoacidosis: International comparison with 49,859 pediatric patients with type 1 diabetes from England, Wales, the U.S., Austria, and Germany. Diabetes Care 2015;38(10):1876-82. https://doi.org/10.2337/dc15-0780

7. Cengiz E, Xing D, Wong JC, et al. Severe hypoglycemia and diabetic ketoacidosis among youth with type 1 diabetes in the T1D Exchange clinic registry. Pediatr Diabetes 2013;14(6):447-54. https://doi.org/10.1111/ pedi.12030

8. British Society of Paediatric Endocrinology and Diabetes. BSPED recommended guideline for the management of children and young people under the age of 18 years with diabetic ketoacidosis 2015. https://www.bsped.org.uk/media/1381/dkaguideline.pdf (last accessed 8 Jan 2019).

9. Wolfsdorf Jl, Glaser N, Agus M, et al. ISPAD clinical practice consensus guidelines 2018: Diabetic ketoacidosis and the hyperglycemic hyperosmolar state. Pediatr Diabetes 2018;19(Suppl 27):155-77. https://doi.org/10.1111/ pedi.12701 
10. Dhatariya K, Savage M, Claydon A, et al. Joint British Diabetes Societies Inpatient Care Group. The management of diabetic ketoacidosis in adults. Second Edition. Update: September 2013. http://www.diabetologistsabcd.org.uk/JBDS/JBDS_IP_DKA_Adults_Revised.pdf (last accessed 8 Jan 2019).

11. Dhatariya KK, Nunney I, Higgins K, Sampson MJ, Iceton G. A national survey of the management of diabetic ketoacidosis in the UK in 2014. Diabet Med 2016;33(2):252-60. https://doi.org/10.1111/dme.12875

12. Edge JA, Nunney I, Dhatariya KK. Diabetic ketoacidosis in an adolescent and young adult population in the UK in 2014: a national survey comparison of management in paediatric and adult settings. Diabet Med 2016;33(10):1352-9. https://doi.org/10.1111/dme.13065

13. American Diabetes Association. Children and adolescents: Standards of medical care in diabetes - 2019. Diabetes Care 2019;42(Suppl 1):S148S164. https://doi.org/10.2337/dc19-S013

14. Peters A, Laffel L; American Diabetes Association Transitions Working Group. Diabetes care for emerging adults: recommendations for transition from pediatric to adult diabetes care systems. Diabetes Care 2011; 34(11):2477-85. https://doi.org/10.2337/dc11-1723

15. NHS Diabetes. Diabetes transition: Assessment of current best practice and development of a future work programme to improve transition process for young people with diabetes. 2013. https://diabetes-resources-production.s3-eu-west-1.amazonaws.com/diabetes-storage/migration/pdf/diabetes-transition-report.pdf

16. NHS Diabetes. Quality standards for transition. 2013. https://diabetesresources-production.s3-eu-west-1.amazonaws.com/diabetes-storage/ migration/pdf/Quality\%2520standards\%2520for\%2520transition.pdf

17. Royal College of Paediatrics and Child Health. School age charts and resources: 2-18 years. 2017. http://www.rcpch.ac.uk/improving-childhealth/public-health/uk-who-growth-charts/school-age-2-18-years/schoolage-charts-an\#2-18 (last accessed 8 Jan 2019).

18. Edge JA, Jakes RW, Roy Y, et al. The UK case-control study of cerebral oedema complicating diabetic ketoacidosis in children. Diabetologia 2006;49(9):2002-9. https://doi.org/10.1007/s00125-006-0363-8

19. Kuppermann N, Ghetti S, Schunk JE, et al. Clinical trial of fluid infusion rates for pediatric diabetic ketoacidosis. N Engl J Med 2018;378(24):227587. https://doi.org/10.1056/NEJMoa1716816

20. Sampson M, Jones C. Joint British Diabetes Societies for Inpatient Care: clinical guidelines and improving inpatient diabetes care. Diabet Med 2018, 35(8):988-91. https://doi.org/10.1111/dme.13672

\section{The Smart Choice for} your Animas users

Roche Diabetes Care believe in choice for patients. Smart Choice is the option of two Accu-Chek insulin pump systems, Accu-Chek Combo and Accu-Chek Insight, ${ }^{*}$ complemented by the Animas to Accu-Chek transition support programme. Our infusion specialists will work closely with you to ensure a smooth transition for your Animas patients.

\section{SQ To find out more visit \\ www.accu-chek.co.uk/smart-choice}

ACCU-CHEK ACCU-CHEKINSIGHT AND COMBO are trademarks of Roche

All other product names and trademarks are property of their respective owners (8. C) 2019 Roche Diabetes Care Limited. All rights reserved

Noche Diabetes Care Limited, Charles Avenue, Burgess Hill, RH15 9RY, UK

Company registration number: 9055599

*Only Accu-Chek Combo available in Ireland

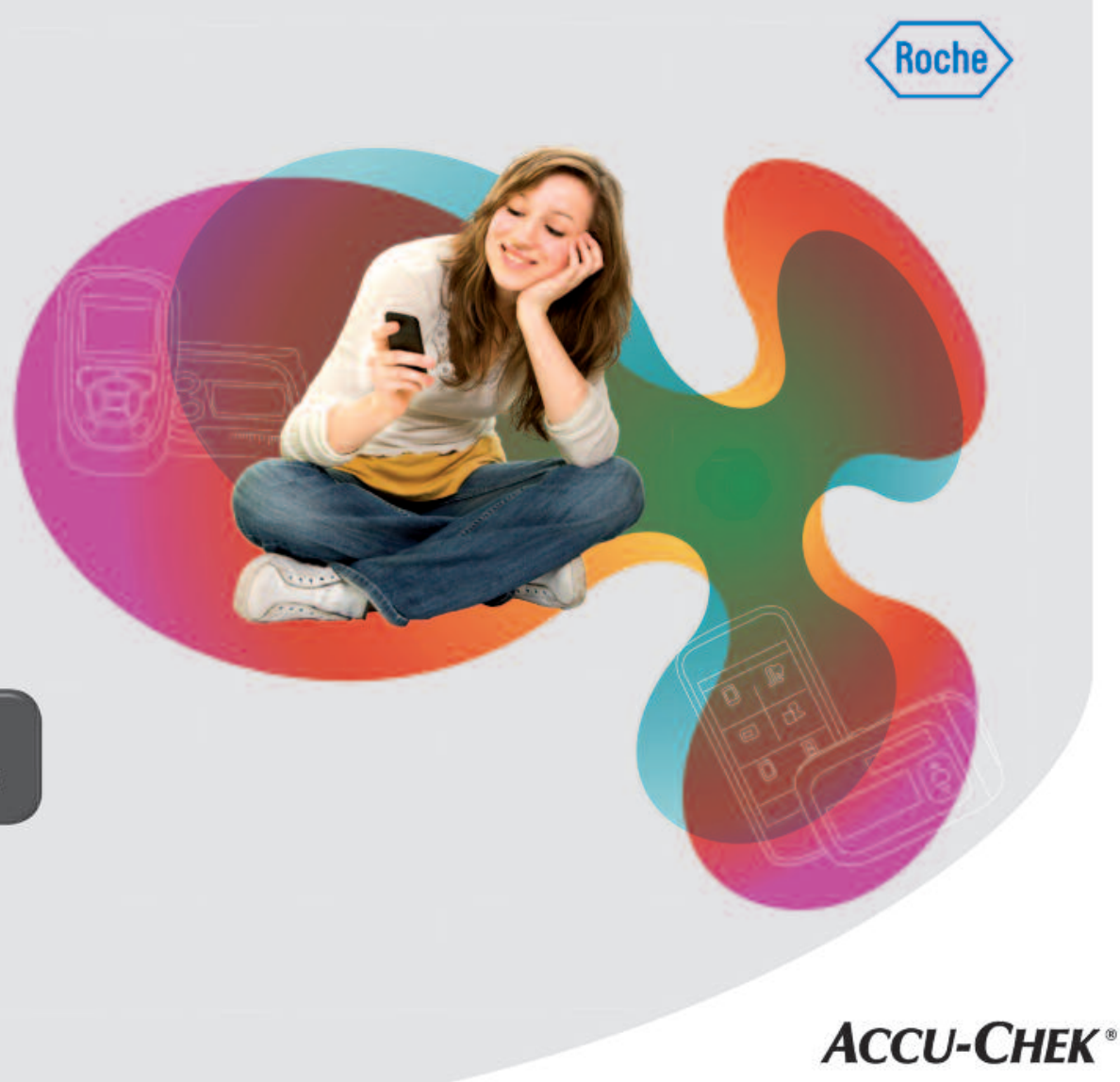


Appendix 1. Questionnaire to look at the care of 16-18-year olds with diabetic ketoacidosis

Questionnaire to look at the care of 16-18 year olds with diabetic ketoacidosis - to be filled out by a junior in A\&E who treats DKA 'at the front door'

Thank you to all of you who have already taken the time to fill this in and send it to us

DEADLINE FOR RETURNING THE QUESTIONNAIRE IS SUNDAY THE $30^{\text {TH }}$ OF SEPTEMBER 2018

The purpose of this questionnaire is to determine how adolescents aged 16-18 years old are looked after when they are admitted to hospital with diabetic ketoacidosis (DKA).

The outpatient care of $16-18$ year olds with diabetes is most frequently carried out by paediatric endocrinologists, general paediatricians with an interest in diabetes and endocrinology, or increasing - in a transition clinic with their adult diabetes colleagues. However, if they are admitted to hospital with diabetic ketoacidosis, then their care is frequently under the care of adult diabetes teams, or general medical teams.

There are national guidelines for the management of DKA for those under 18 - produced by BSPED/ACDC or ISPAD and from JBDS for those aged over 18.

However, there is uncertainty about how many adult teams use the BSPED/ACDC/ISPAD guidelines when managing DKA in those aged 16-18 under their care. Hence this questionnaire - which is supported by ABCD, BSPED and RCPCH.

If these data show a need, then the idea would be to try and produce a single guideline to cover the management of DKA in children and adults.

Thank you for taking the time to fill in this questionnaire

Please send a copy of this completed questionnaire - TOGETHER WITH A COPY OF THE DKA GUIDELINE USED FOR 16-18 YEAR OLDS IN YOUR TRUST to

ketan.dhatariya@nhs.net or in the post to:

Dr Ketan Dhatariya, Consultant in diabetes, endocrinology and general medicine

Elsie Bertram Diabetes Centre, Norfolk and Norwich University Hospitals NHS Foundation Trust, Colney Lane, Norwich, NR4 7UY

Dr Andy Raffles, Honorary Consultant Paediatrician, East and North Herts Institute of Diabetes and Endocrininology (ENHIDE), East and North Herts NHS Trust, Howlands Clinic, New QE2 Hospital, Welwyn Garden City, Herts AL7 4HQ

With support from

Dr Dinesh Nagi, Chair ABCD

Dr Fiona Campbell, RCPCH Officer for Diabetes 
Appendix 1. Questionnaire to look at the care of 16-18-year olds with diabetic ketoacidosis (continued)

Q1

In which hospital Trust do you work?

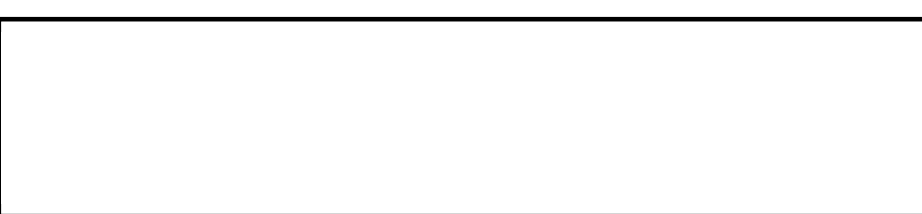

Q2 (Please share this questionnaire with any colleagues in ED/Emergency Medicine,/Children's ED

or admissions unit who may be responsible for the initial care of a C\&YP aged under 18 with DKA)

Are you a?

FY1

FY2

CMT

ST

$\mathrm{SpR}$

Consultant

Other (please specify)

Q3

How is ' 16 to 18 years old' defined in your institution?

From the date of their $16^{\text {th }}$ birthday to the date of their $18^{\text {th }}$ birthday (i.e. up to 18 years old)

From the date of their $16^{\text {th }}$ birthday to the day before their $19^{\text {th }}$ birthday (i.e.

including 18 year olds)

It varies

Don't know

Something else (please specify) 
Appendix 1. Questionnaire to look at the care of 16-18-year olds with diabetic ketoacidosis (continued)

\section{Q4}

If a 16 to 18 year old is admitted to your hospital with suspected or biochemically confirmed diabetic ketoacidosis, which team are they most likely to be handed over to by the emergency department?

$\square$ The adult diabetes team

$\square$ The paediatric diabetes team

$\square$ A general adult medical team

$\square$ A general paediatric team

$\square$ ITU / HDU / PICU

$\square$ Don't know

$\square$ A combination (please specify)

$\square$ Other (please specify)

Q5

Once they are stabilised and ready to go to a general ward, which team would they be admitted under?

$\square$ The adult diabetes team

$\square$ The paediatric diabetes team

$\square$ A general adult medical team

$\square$ A general paediatric team

$\square$ ITU / HDU / PICU

$\square$ Don't know

$\square$ A combination (please specify)

$\square$ Other (please specify)

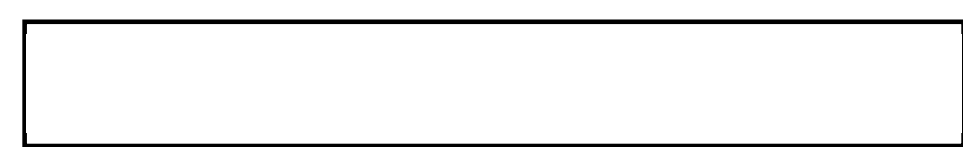

3 | P a g e 
Appendix 1. Questionnaire to look at the care of 16-18-year olds with diabetic ketoacidosis (continued)

\section{Q6}

If a 16 to 18 year old is admitted to your hospital with suspected or biochemically confirmed diabetic ketoacidosis what guideline do you use to manage their DKA?

The Joint British Diabetes Society (JBDS) guideline (or locally adapted)

(http://www.diabetologists-abcd.org.uk/JBDS/JBDS_IP_DKA_Adults_Revised.pdf).

$\square$ The British Society of Paediatric Endocrinology and Diabetes (BSPED)/

Association of Children's Diabetes Clinicians (ACDC) guideline (or locally adapted)

(https://www.bsped.org.uk/media/1381/dkaguideline.pdf).

The International Society of Paediatric and Adolescent Diabetes (ISPAD)

guideline (or locally adapted).

(https://c.ymcdn.com/sites/www.ispad.org/resource/dynamic/forums/20171214_0447

\section{1_30120.pdf)}

Local regional network approved guideline **

Your own Trust guideline **

Other (please specify) **

${ }^{* *}$ Please attach and send a copy of the guideline together with this completed questionnaire to ketan.dhatariya@nhs.net) 
Appendix 1. Questionnaire to look at the care of 16-18-year olds with diabetic ketoacidosis (continued)

\section{Q7}

Do the adult teams treating 16-18 year olds know about the BSPED/ACDC/ISPAD

guidelines?

$\square$ Yes

$\square$ No

$\square$ Don't know

Other (please specify)

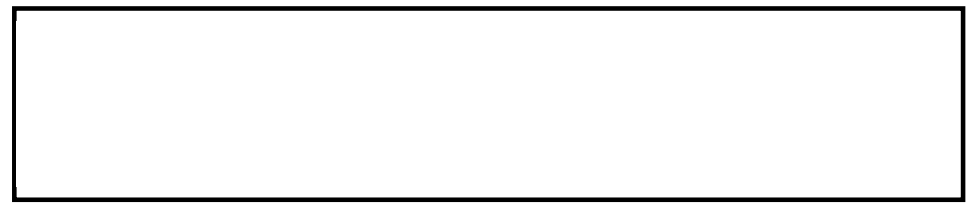

Q8

If the adult teams looking after 16-18 year olds with DKA know about the

BSPED/ACDC/ISPAD guidelines, why are they not used?

$\square$ They are too complicated

$\square$ The adult (JBDS) guideline is easier to use

We have our own local guideline for this age group

Not used frequently enough to be as familiar with them as the JBDS guideline

$\square$ Not applicable

$\square$ Other (please specify)

\section{Q9}

Do the paediatric teams ever use the adult (JBDS) guideline for 16-18 year olds?

\section{Yes}

No

\section{Don't know}

Other (please specify)

5 I P g g 
Appendix 1. Questionnaire to look at the care of 16-18-year olds with diabetic ketoacidosis (continued)

\section{Q10}

Why do paediatric teams use the adult (JBDS) guideline for 16-18 year olds?

$\square$ Not aware of the BSPED/ACDC/ISPAD guidelines

The individual is 'adult sized'

All 16 year olds are treated as adults by our Trust when inpatients regardless of their admission diagnosis

$\square$ Not applicable

$\square$ Other (please specify)

\section{Q11}

Do you think that a joint guideline for managing DKA in children and adults would be useful?

$\square$ Yes - definitely

$\square$ Yes - maybe

$\square$ Not sure

$\square$ No - probably not

$\square$ No - definitely

Why do you say this?

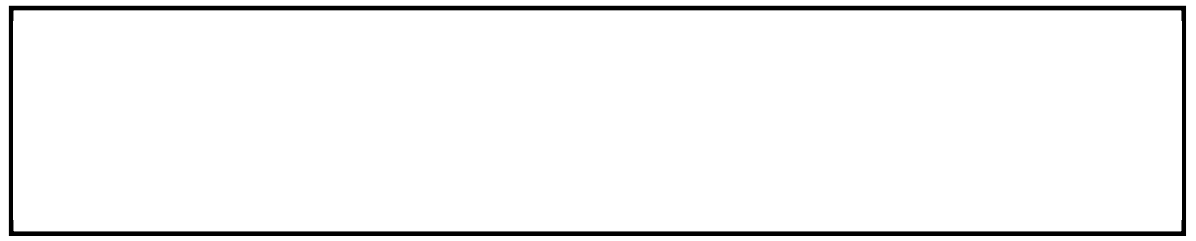

6 I P a g e 
Appendix 1. Questionnaire to look at the care of 16-18-year olds with diabetic ketoacidosis (continued)

\section{Q12}

Do you routinely weigh patients admitted with DKA?

Aged $0-15$ years $\quad$ Yes $\square \quad$ No $\square$

Aged $16-18$ years $\quad$ Yes $\square \quad$ No $\square$

Aged over 18 years $\quad$ Yes $\square \quad$ No $\square$

\section{Q13}

The following fluids are recommended by the BSPED/ACDC/ISPAD guidelines

Are they available in the areas where 16-18 year olds are treated for DKA?

$0.9 \%$ sodium chloride solution ("normal saline")

$0.45 \%$ sodium chloride solution ("half-normal saline")

$2.7 \%$ sodium chloride solution

$3 \%$ sodium chloride solution

Mannitol

$\begin{array}{ll}\text { Yes } \square & \text { No } \square \\ \text { Yes } \square & \text { No } \square \\ \text { Yes } \square & \text { No } \square \\ \text { Yes } \square & \text { No } \square \\ \text { Yes } \square & \text { No } \square\end{array}$

Q14

Does your institution allow for paediatric and adult joint working - e.g. do you have a joint guideline or an inpatient paediatric / adolescent / adult MDT that sees these inpatients together?

Yes (please elaborate)

No

\section{Don't know}

Other (please specify)

7| P a g e 
Appendix 1. Questionnaire to look at the care of 16-18-year olds with diabetic ketoacidosis (continued)

\section{Q15}

In your institution are 16-18 year olds formally reviewed by the diabetes specialist team (adult or adolescent) prior to discharge?

Yes

No

Sometimes

Don't know

Other (please specify)

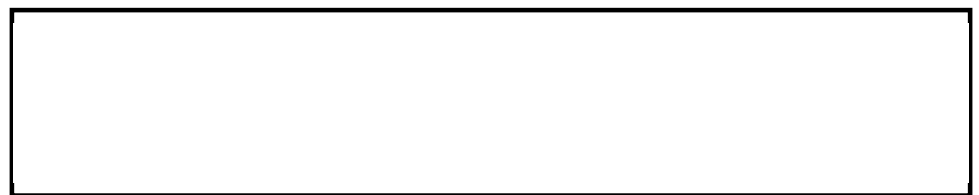

Thank you for filling out this questionnaire

Please send a copy of this completed questionnaire - TOGETHER WITH A COPY

OF THE DKA GUIDELINE USED FOR 16-18 YEAR OLDS IN YOUR TRUST to

ketan.dhatariya@nhs.net

Or in the post to:

Dr Ketan Dhatariya, Consultant in diabetes, endocrinology and general medicine

Elsie Bertram Diabetes Centre, Norfolk and Norwich University Hospitals NHS

Foundation Trust, Colney Lane, Norwich, NR4 7UY

8 I P a g e 